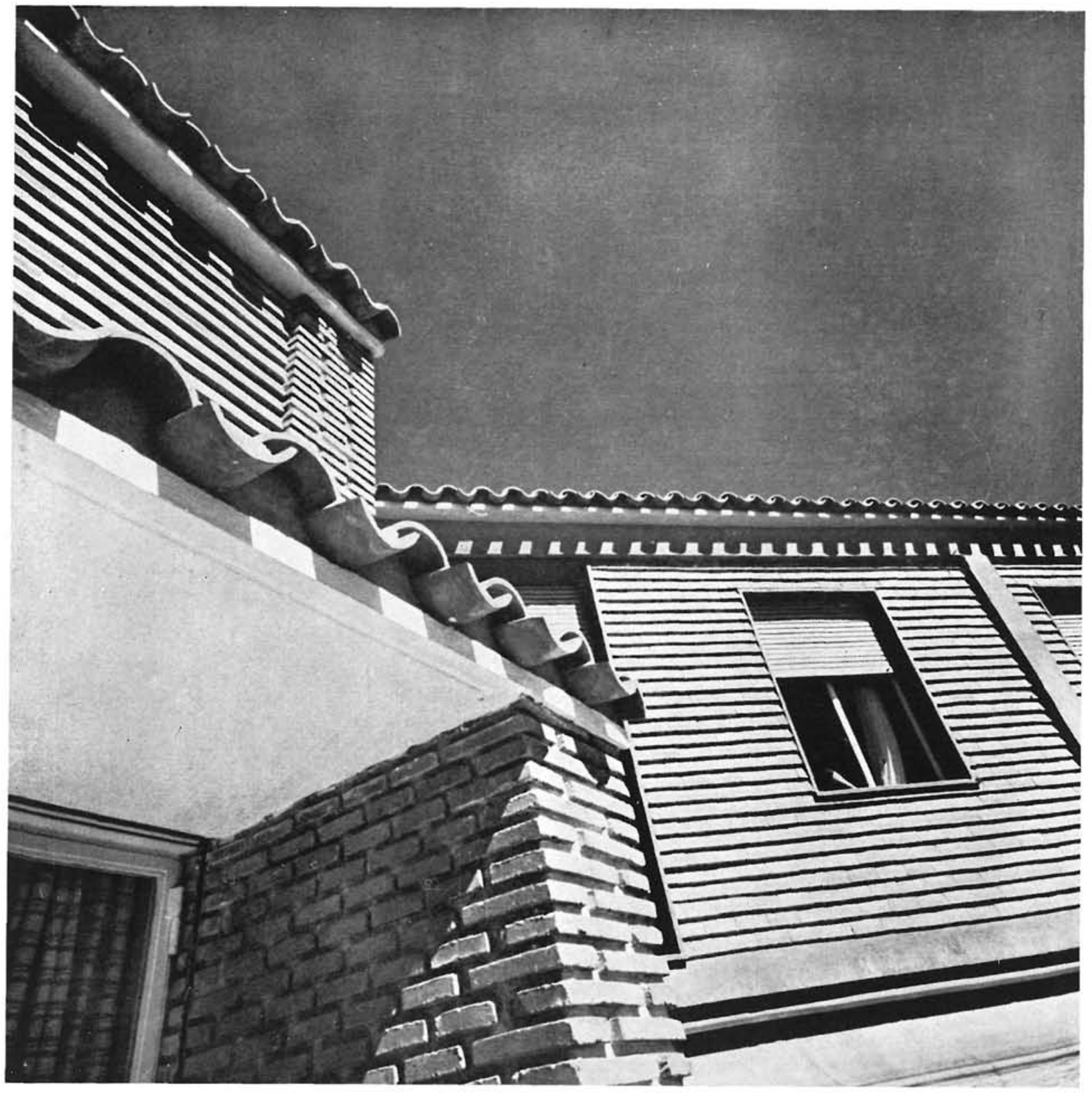

\title{
vivienda unifamiliar, en Madrid
}

MIGUEL FISAC, arquitecto

INSTITUTO TECNICO DE LA CONSTRUCCION Y DEL CEMENTO 

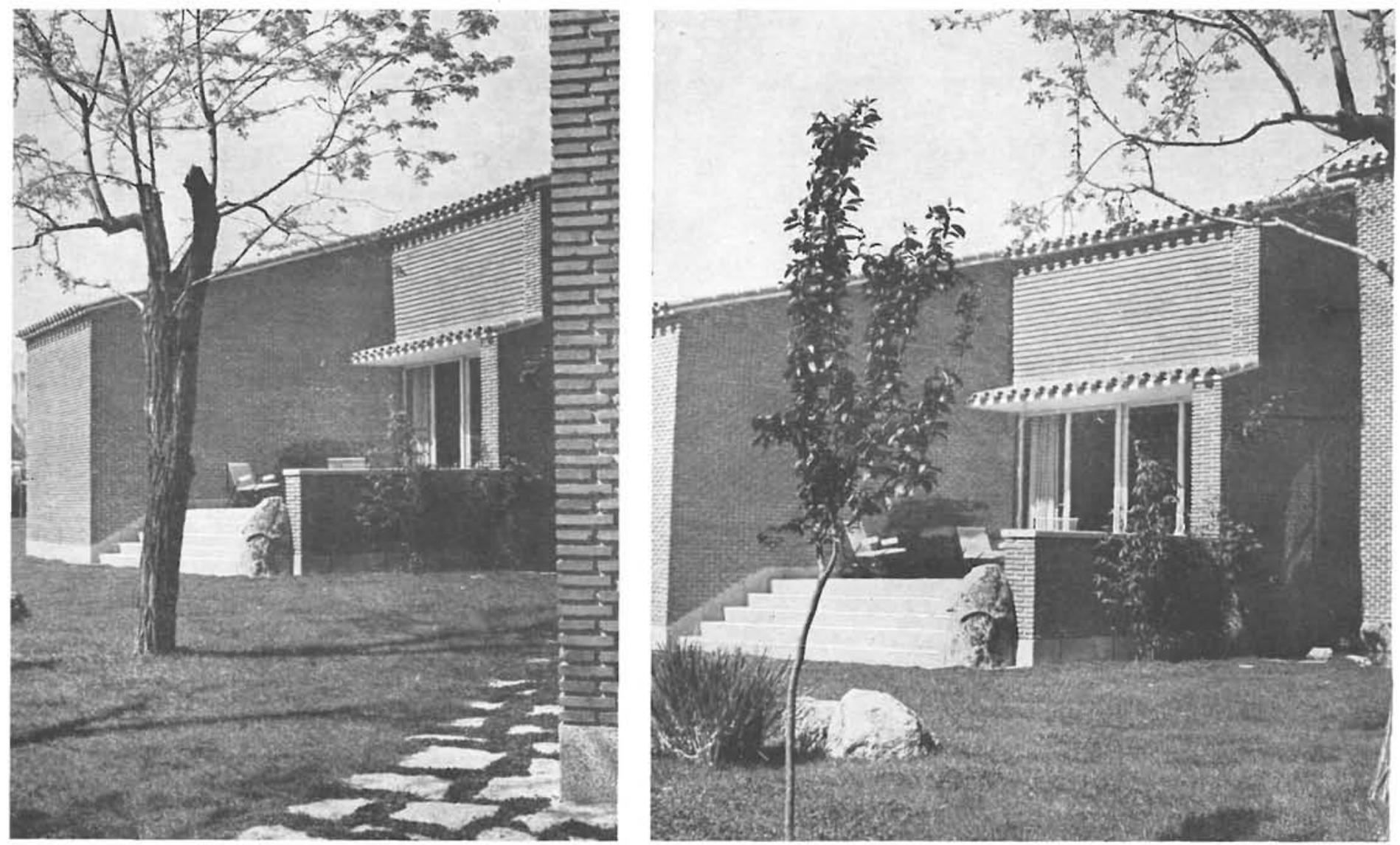

Es difícil, no contando en España con una industria de la construcción que esté al día, edificar con la gracia y el sentido de hoy. Entre los muchos inconvenientes que este atraso nos ocasiona, surgen, sin embargo, algunas ventajas. Con la falta de «standarización» nuestras construcciones son de estricta artesanía, lo que permite que se hagan más perfectamente a la medida del que las va a habitar, que si tuviera que adaptarse a una modulación ya prefabricada.

Esta construcción es la vivienda de una familia que quiere vivir así. En contraste a la diafanidad y a la claridad de enlace de los espacios de vivir-estar, comedor, bar-, se opone, con excesivo contraste, otras zonas compartimentadas, que originan pasillos y escaleras que tal vez el arquitecto hubiera querido reducir o suprimir totalmente. No se puede negar, sin embargo, que esa distribución facilita el aislamiento y, como consecuencia, el confort. Un confort no mecanizado, pero muy práctico desde el punto de vista doméstico.

La forma y disposición del edificio responde a la más estricta conveniencia de orientación y de ubicación en el terreno, sin concesiones a una estética formal preconcebida. La estructura y los materiales empleados responden también a esta completa honradez de concepto. 


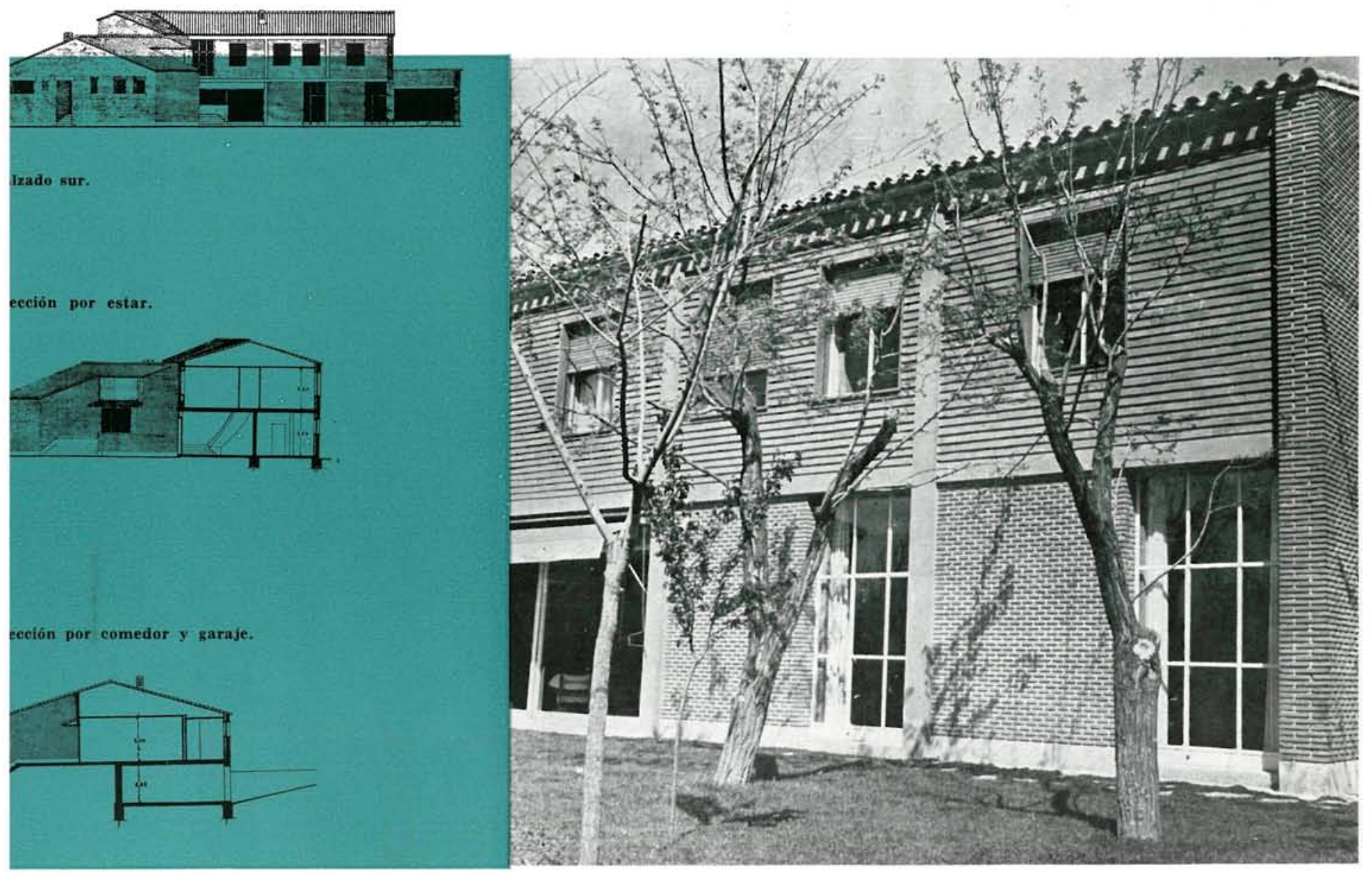

achada mediodía

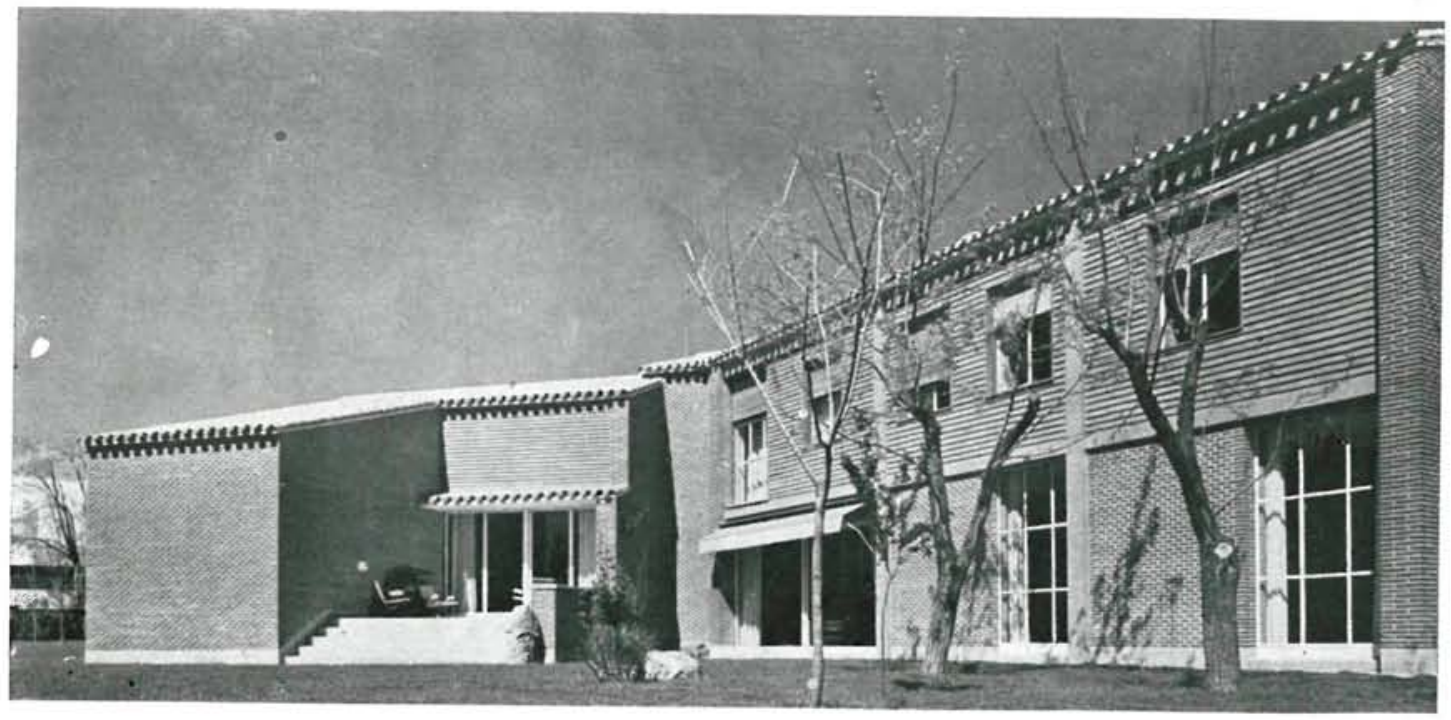




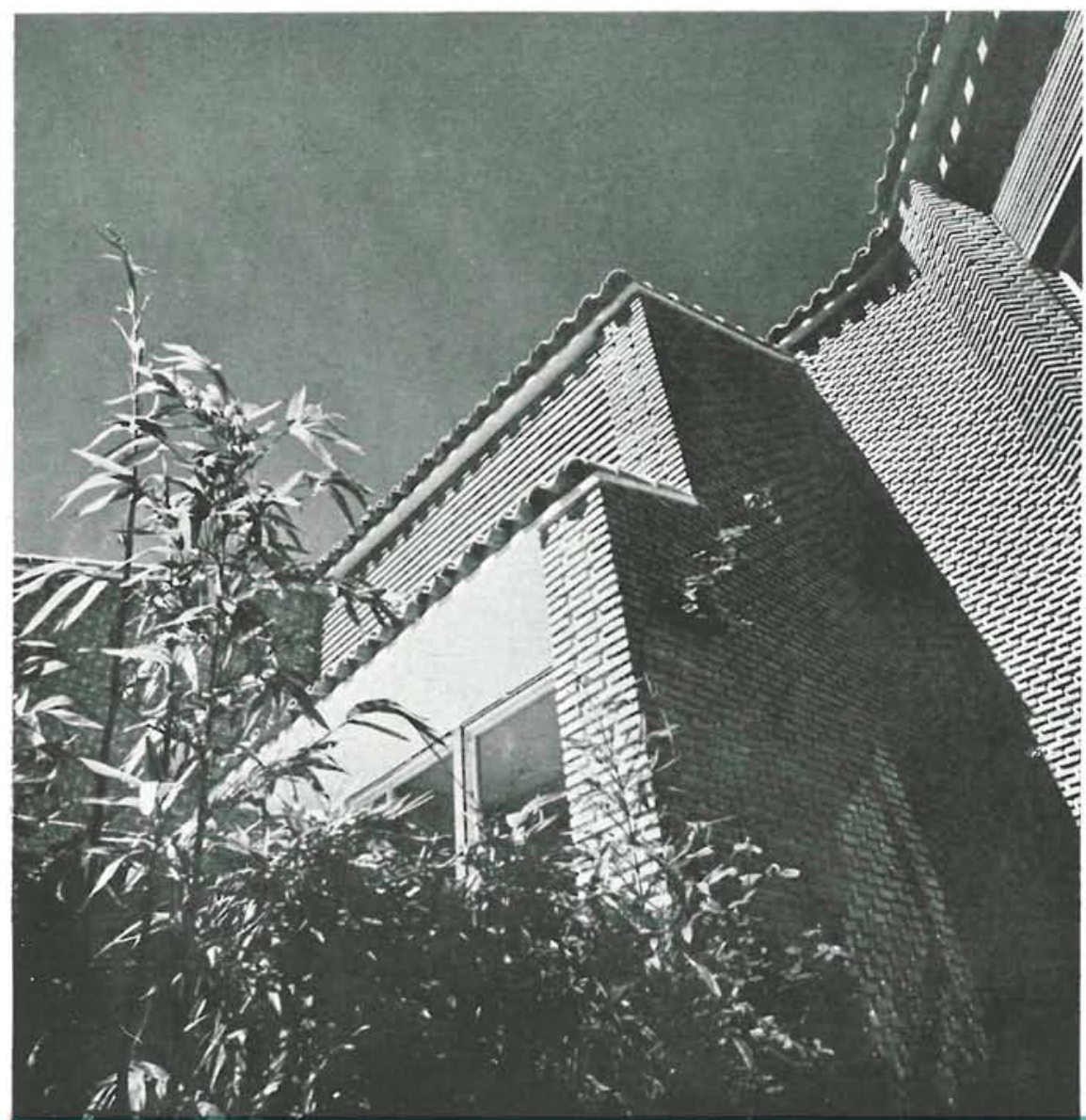

fachada mediodía
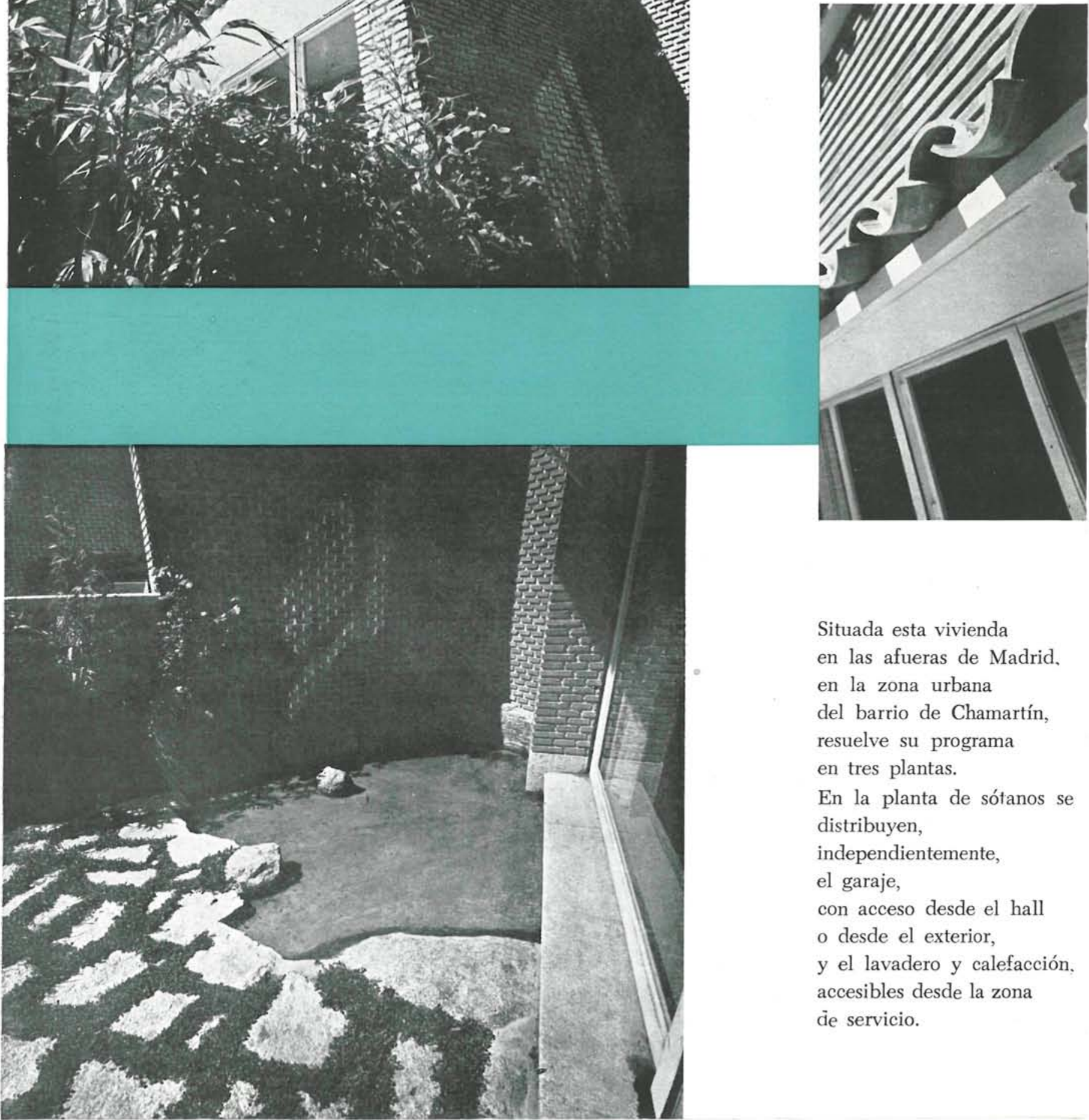

Situada esta vivienda en las afueras de Madrid, en la zona urbana del barrio de Chamartín, resuelve su programa en tres plantas.

En la planta de sótanos se distribuyen,

independientemente, el garaje, con acceso desde el hall o desde el exterior, y el lavadero y calefacción. accesibles desde la zona de servicio. 


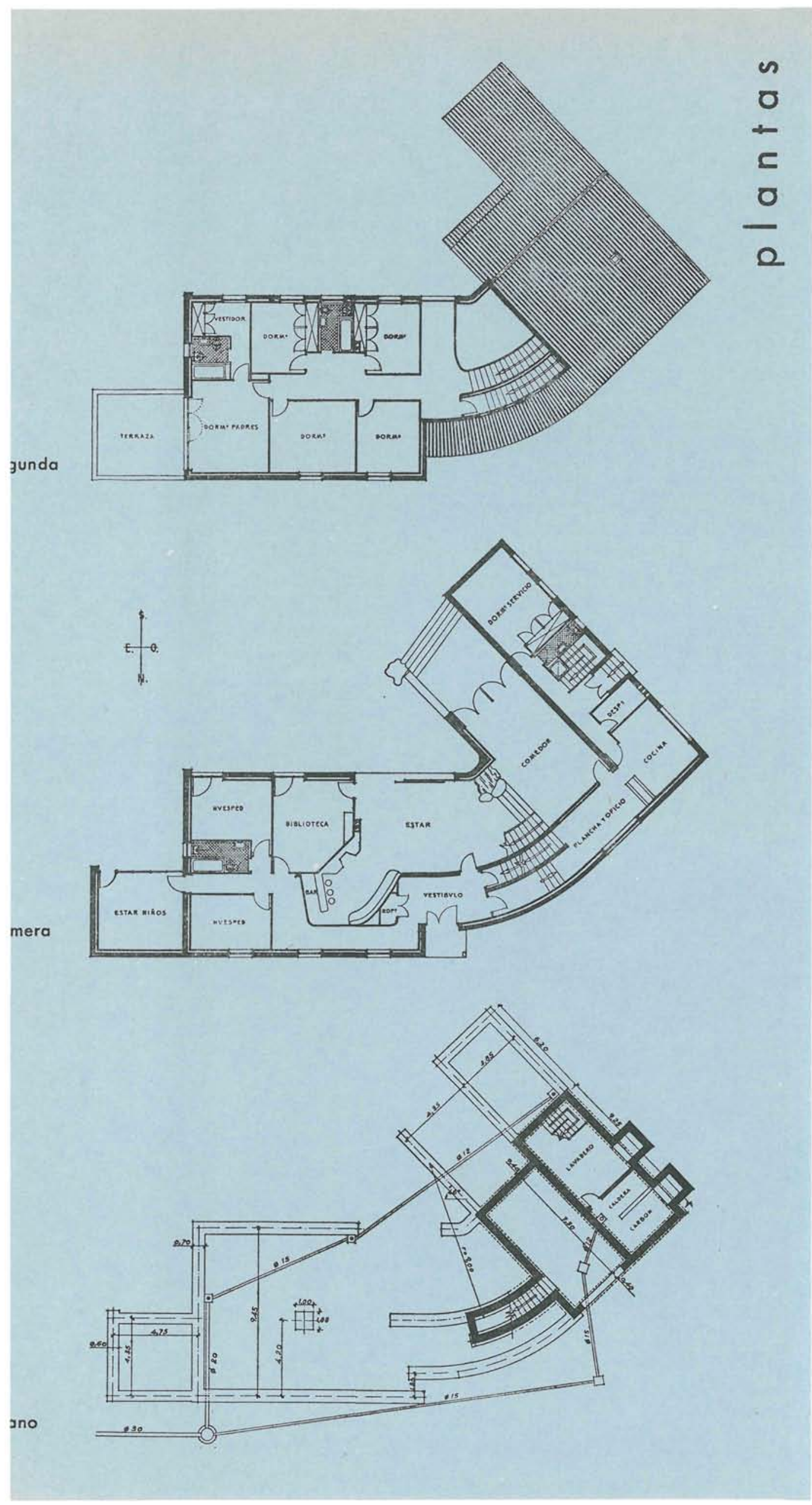


0
$\leftarrow$
0
1
$E$
0
$\vdots$
0
0
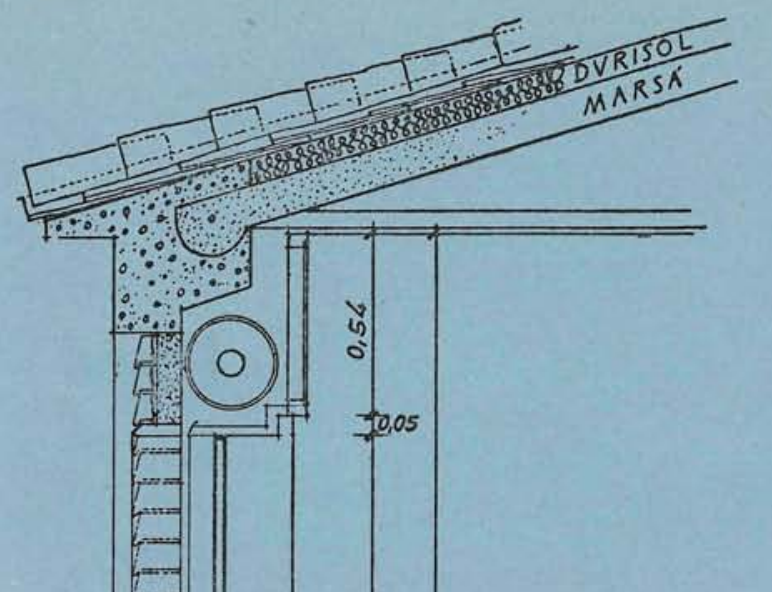

$+3,38$

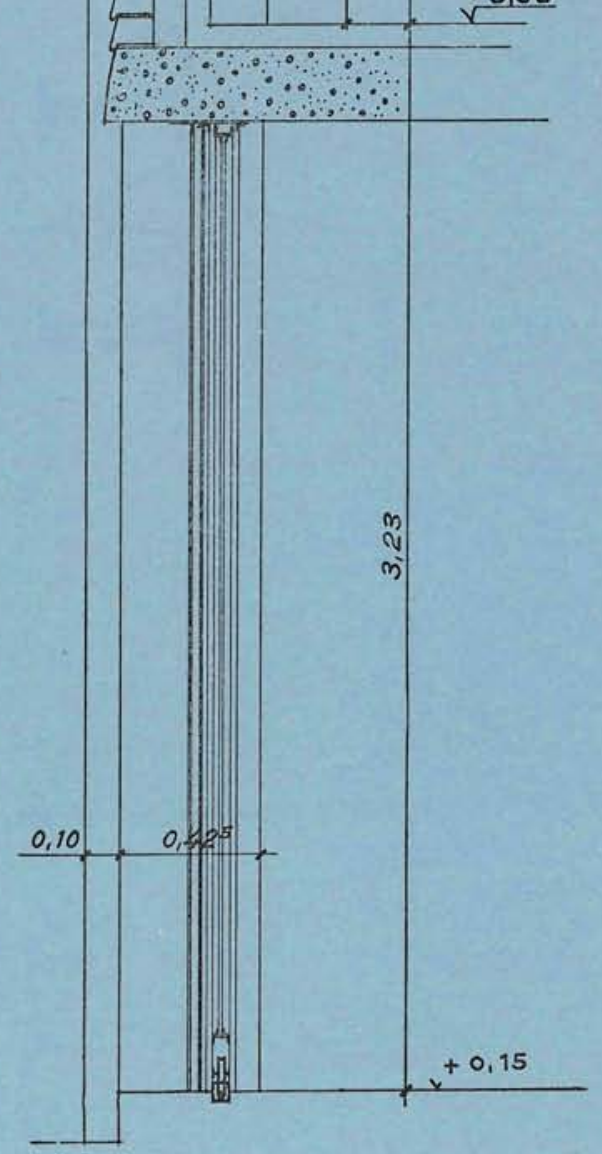

sección

por la biblioteca 


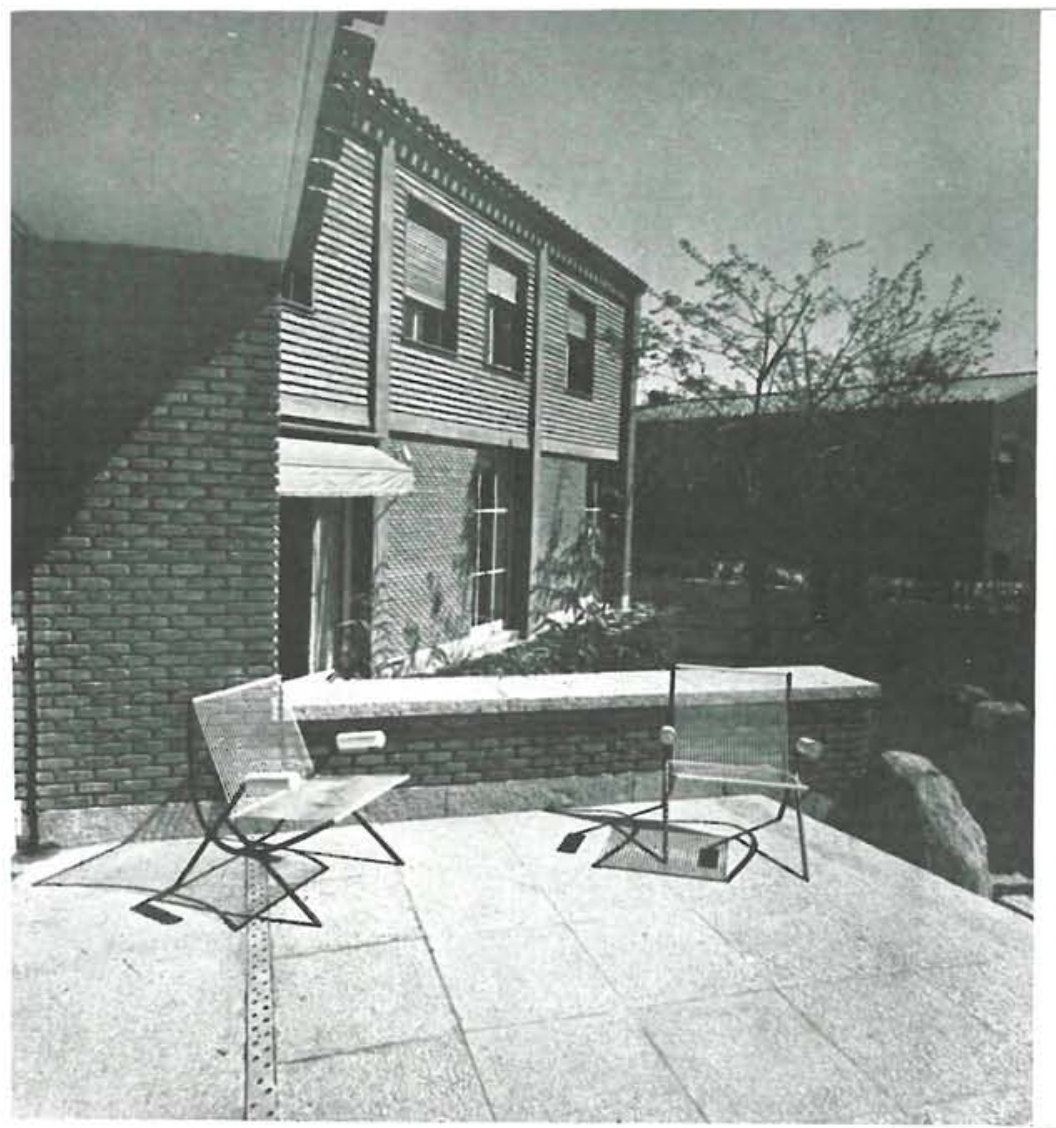

En planta baja, ocupa el núcleo central la zona del estar-comedor, ampliamente abierta hacia el jardín, mediante grandes vidrieras, que, protegidas del sol por medio de toldos de lona abatibles, permiten la continuidad de espacio interior y exterior,

felizmente resaltada por medio de la terraza, pequeños estanques, vegetación interior y continuidad de paramentos de fábrica de ladrillo.
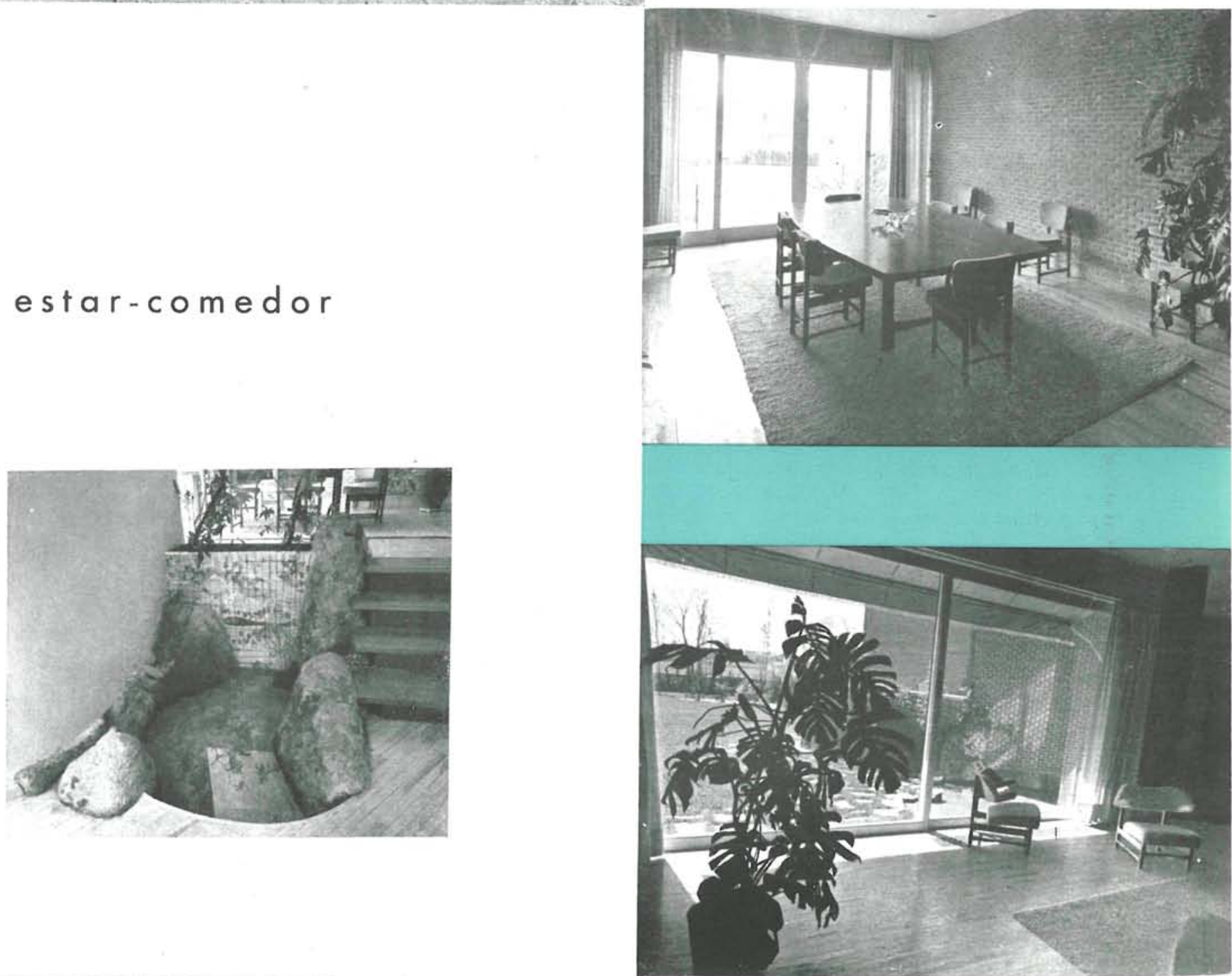


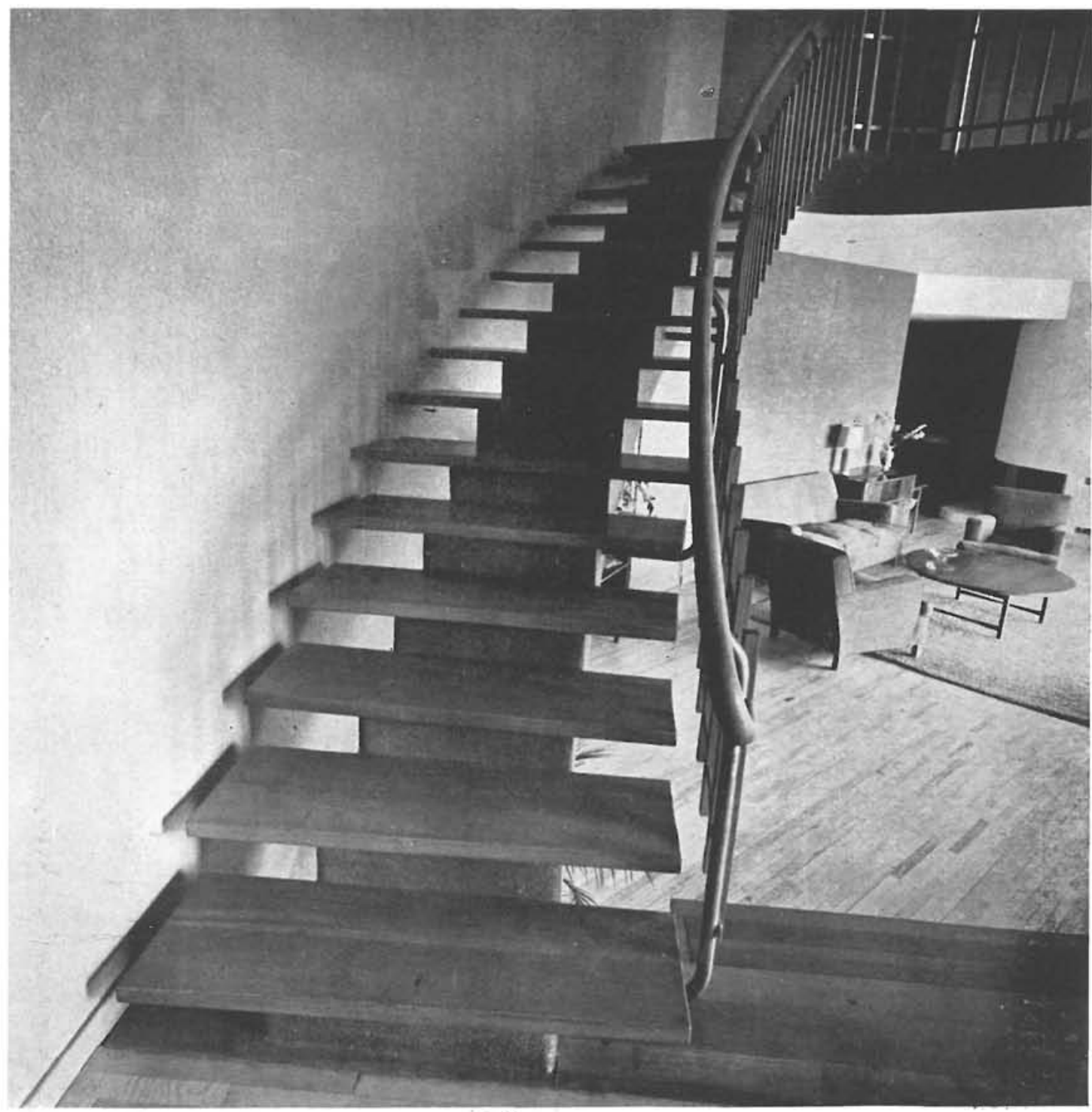

escalera

El comedor, elevado unos peldaños sobre el estar, se enlaza al oeste, y a través del oficio, con la cocina.

$\mathrm{El}$ ala este está ocupada por la biblioteca y dormitorios de huéspedes, y en su extremo se encuentra la habitación para juegos de niños.

El enlace con la planta superior se efectúa por medio de dos escaleras independientes y paralelas, de planta curva. La principal, con zanca de hormigón armado y peldaños volados de huellas de madera sin tabicas, es de línea elegante y airosa, sirviendo de elemento de composición del estar, junto con el pequeño estanque, decorado con azulejos, obra del escultor Gabino.

En la planta superior, sólo se distribuyen los dormitorios de la familia.

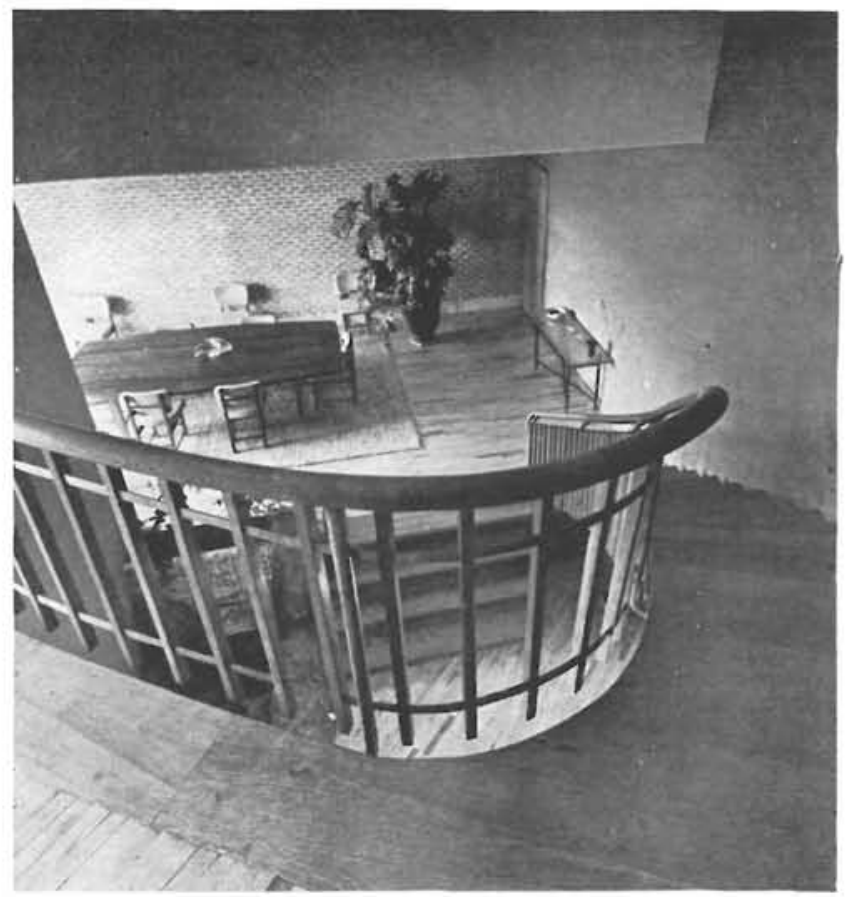




\section{planta y sección}

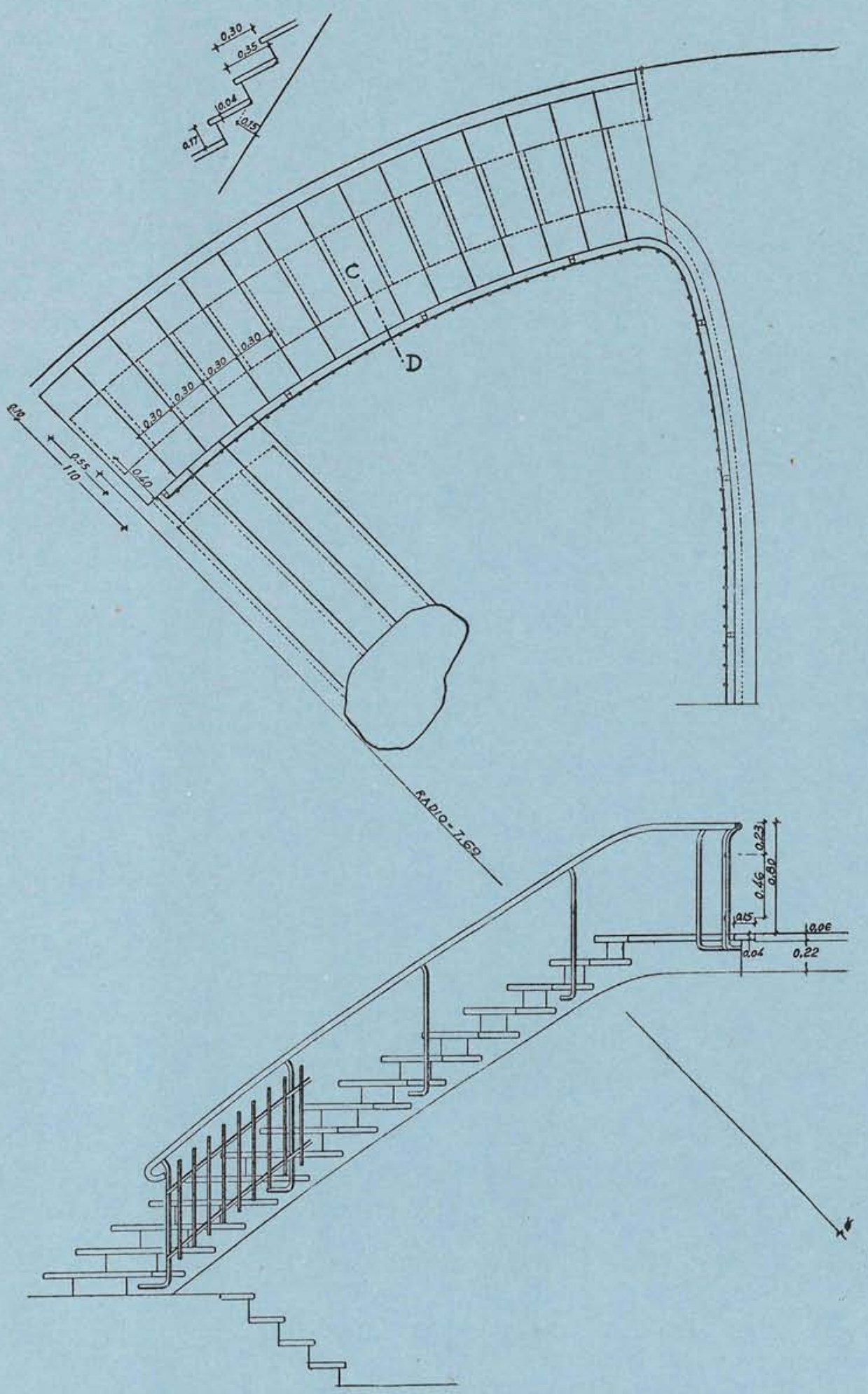




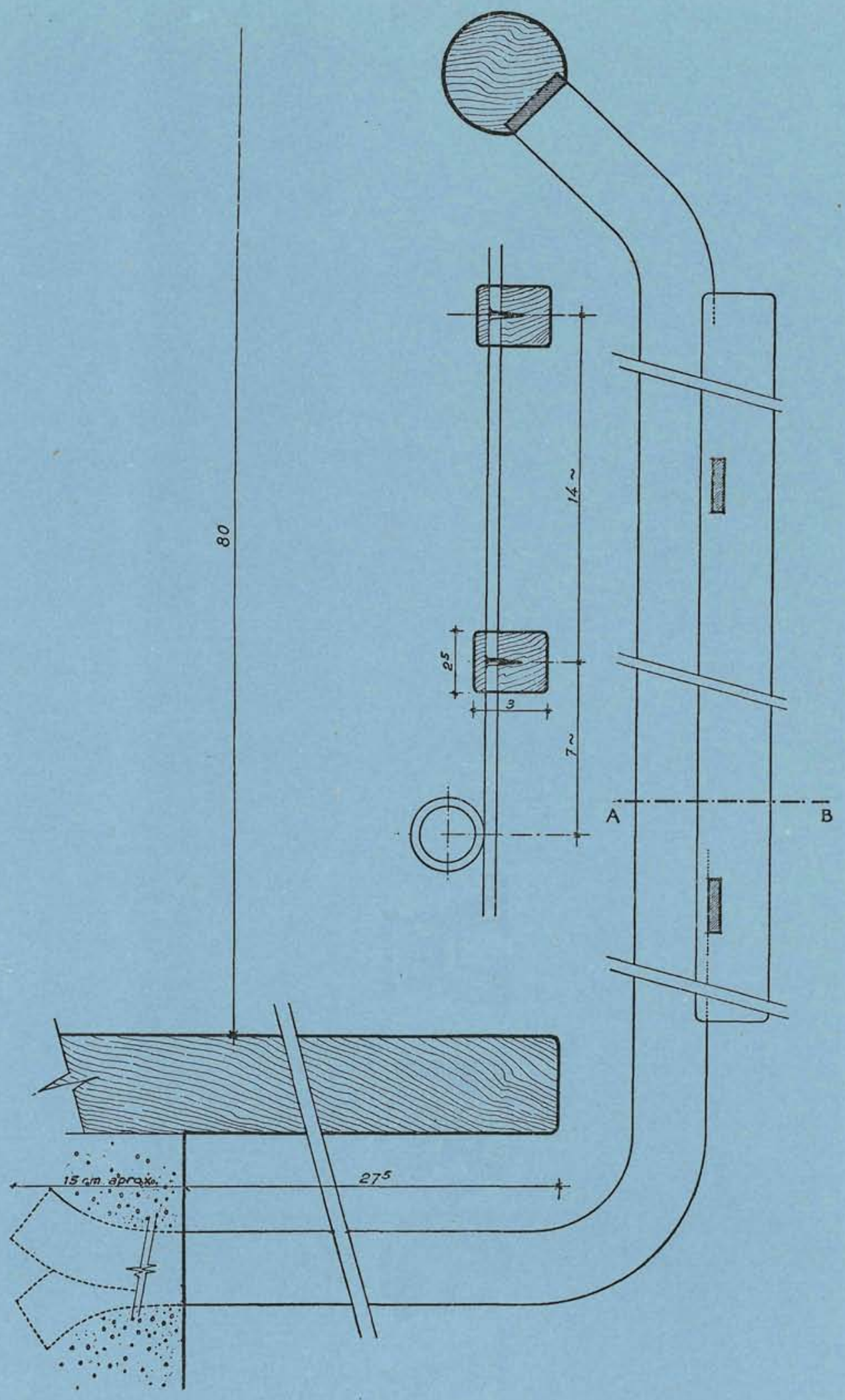

detalle de barandilla 


\section{escalera}

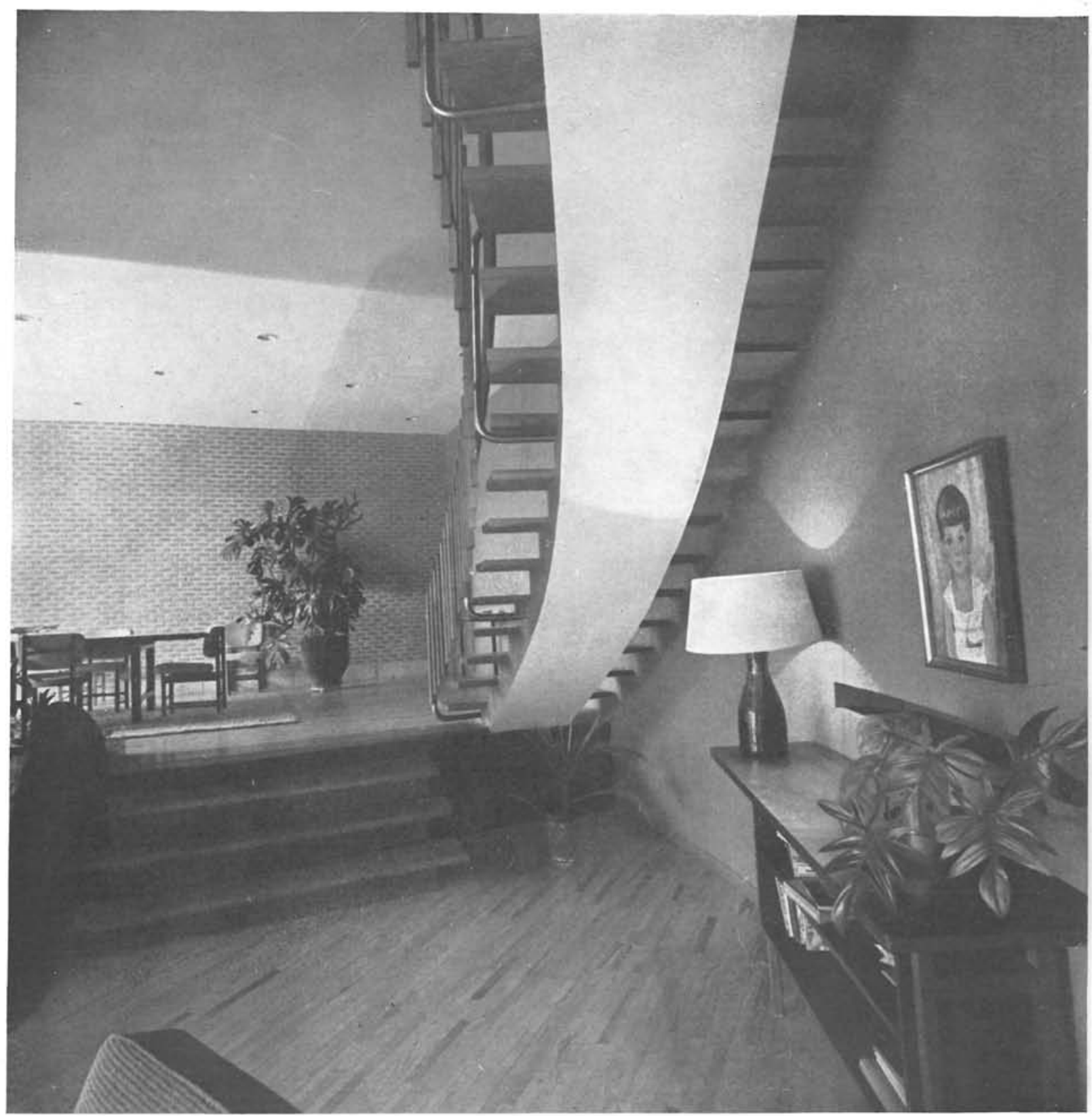

Es de destacar en esta obra la sinceridad constructiva de la misma,

que ha permitido crear una solución llena de actualidad,

con materiales tan tradicionales como la teja árabe y la fábrica de ladrillo macizo con aparejo «a la española».

Los muros que sólo cumplen una función de cerramiento

han sido construídos con ladrillo especial tipo ceja, patente del autor de la obra. 


\section{fachada norte}

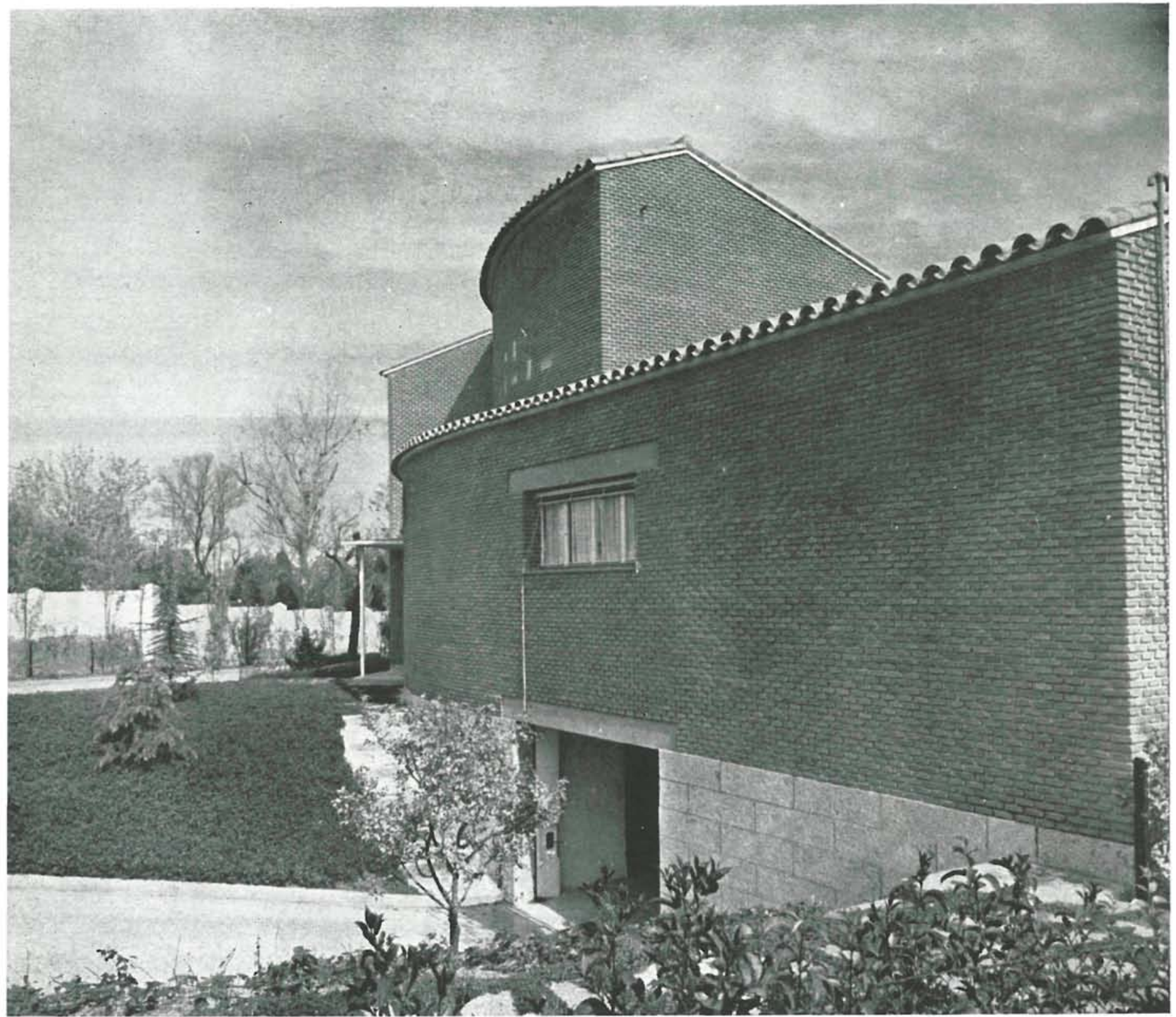

Tanto la distribución de sus plantas como la composición de masas, ponen de manifiesto la clara idea funcional que presidió la concepción de esta obra, la cual, magníficamente ambientada por las zonas ajardinadas que la rodean, constituye un claro ejemplo de arquitectura no pretenciosa, concebida con gran sentido ordenador y constructivo para satisfacer un programa familiar concreto a gusto de su propietario. 